\title{
Can more efficient use be made of $x$ ray examinations in the accident and emergency department?
}

\author{
D N S GLEADHILL, J Y THOMSON, P SIMMS
}

\begin{abstract}
Increasing workloads in our radiology department prompted a study of casualty officers' use of $x$ ray examinations, of which there were 5463 in the period. While casualty officers were in post referrals for $x$ ray examination did not become more selective, but skills in interpreting films improved. Overall, $4.9 \%$ of trauma radiographs were misinterpreted, but this fell from $7 \cdot 1 \%$ to $2 \cdot 9 \%$ during tenure of post. One in four errors was clinically important. Clinical guidelines for selective radiography produced a significant and sustained reduction in the number of $x$ ray examinations requested by the department. Analysis of one common injury indicated that the quality of patient care was not adversely affected.

The number of $x$ ray examinations carried out in the accident and emergency department can be reduced by using guidelines, and this does not compromise the quality of patient care. Appreciable savings may be made in patients' waiting times and radiodiagnostic expenditure.
\end{abstract}

\section{Introduction}

The means and merits of selecting patients for radiography in accident and emergency departments ${ }^{1-11}$ and the radiological skills of casualty officers and radiologists ${ }^{12-17}$ have been studied recently. In these studies ways have been sought to reduce the number of both

Accident and Emergency Department, Walton Hospital, Liverpool L9 1AE D N S GLEADHILL, MRCP, FRCS, senior registrar

J Y THOMSON, MRCGP, consultant

P SIMMS, FRCS, consultant

Correspondence to: $\mathrm{Mr}$ Gleadhill. needless $x$ ray examinations and needless reporting. We carried out a two part study: ( $a$ ) to determine whether the selection of patients for $x$ ray examination and the radiological skills of casualty officers alter during tenure of post and $(b)$ to determine whether introducing clinical guidelines on referring patients for $x$ ray examination influences the number being requested by the department.

A common problem for $x$ ray departments is the increasing numbers of patients being referred for examination. ${ }^{18-20}$ In some reports it has been suggested that the problem is particularly acute in accident and emergency departments..$^{18}$ Our department has not escaped this "epidemic"; the number of $x$ ray examinations has risen inexorably in recent years.

\section{Methods}

Twelve casualty officers, all senior house officers, entered the study. Six were in their first postregistration job, five had completed one year as senior house officer in specialties in acute wards, and one had come from a registrar post in neurosurgery. This doctor had not worked in accident and emergency medicine for some years and felt he was unfamiliar with much of the clinical material. Overall, the level of experience in the specialty was considered uniform and similar to other groups starting such posts.

Junior hospital doctors who embark on their first senior house officer post in accident and emergency medicine often have little or no experience in treating trauma, especially "minor" trauma. Those who are appointed to our department receive instruction through a teaching programme before and during their attachment (table I).

Patients' records were examined during a six month period. A register was made for each casualty officer, whose accumulating experience was gauged not by the amount of time spent in the department but by the number of injuries seen. Injuries rather than patients were monitored since some patients had more than one injury. Comparisons were made for each 100 injuries seen (one "unit of experience") up to a total of 700 injuries (seven units of experience). Patients' records were analysed according to the algorithm shown in figure 1 . A qualitative analysis was made of all injuries so that any bias between groups of patients in terms of " $x$ rayability" would be 
detected. "Non- $x$ rayable" injuries were simple lacerations, abrasions, burns, bites, and stings. For different units of experience $74.6 \%$ (895 of 1200 ) to $77 \cdot 3 \%$ (928 of 1200 ) of injuries were $x$ rayable. This variation was not significant (total $\chi^{2}=4.37,6 \mathrm{df}, \mathrm{p}=0.63 ; \chi^{2}$ for trend $=0.07,1 \mathrm{df}, \mathrm{p}=$ $0 \cdot 80$ ). The radiologist's report was considered "positive" if it described abnormality related to the trauma. The percentage of radiographs that was positive (abnormal) indicated referral selectivity.

\section{INTERPRETATION OF RADIOGRAPHS}

Figure 1 shows how data were obtained for assessing the radiological skill of each casualty officer. The casualty officer's recorded interpretation was compared with the radiologist's report, which was considered the correct interpretation. (A few exceptions were resolved by a panel of an accident and emergency consultant and a consultant radiologist.) Errors in interpretation may be false positive (a normal radiograph is interpreted as abnormal) or false negative (an abnormal radiograph is interpreted as normal). False negative interpretations may be "clinically unimportant" (treatment and outcome unaffected) or "clinically important" (treatment or outcome, or both, affected by the error). False positive errors, although unfortunate, rarely cause more than annoyance and were considered clinically unimportant.

TABLE -Instruction programme for accident and emergency officers in this department

(1) Regional introductory course in accident and emergency medicine, two weeks before starting appointment (one day)

(2) Departmental introductory day of instruction (first day of appointment)

(3) Teaching programme throughout six months of appointment. Weekly seminar: (a) Visiting speakers (includes two sessions on $x$ ray examinations) (b) $x$ Ray film audit (all errors reviewed)

(c) Journal review (d) Case reports

(4) "Specials" attachment (one week). One day of this week is devoted to radiograph reporting with a consultant radiologist

(5) Department handbook (76 pages of clinical notes) issued to all casualty officers

(6) Opinion of senior accident and emergency staff or radiologist encouraged if casualty officer in doubt

TABLE II-Number of new attendances and x ray referrals, 1982-6

\begin{tabular}{|c|c|c|c|}
\hline Year & $\begin{array}{c}\text { No of new } \\
\text { attendances }\end{array}$ & $\begin{array}{c}\text { No of patients } \\
x \text { rayed }\end{array}$ & $\begin{array}{c}\text { Total } \\
\text { referral rate (\%) }\end{array}$ \\
\hline \multicolumn{4}{|l|}{ 1982: } \\
\hline $\begin{array}{l}\text { Jan-June } \\
\text { July-Dec }\end{array}$ & $\begin{array}{l}33374 \\
32069\end{array}$ & $\begin{array}{l}17190 \\
17210\end{array}$ & $\begin{array}{l}51 \cdot 5 \\
53 \cdot 7\end{array}$ \\
\hline \multicolumn{4}{|l|}{ 1983: } \\
\hline $\begin{array}{l}\text { Jan-June } \\
\text { July-Dec }\end{array}$ & $\begin{array}{l}33532 \\
35234\end{array}$ & $\begin{array}{l}17679 \\
18998\end{array}$ & $\begin{array}{l}52 \cdot 7 \\
53 \cdot 9\end{array}$ \\
\hline 1984: & & & \\
\hline $\begin{array}{l}\text { Jan-June } \\
\text { July-Dec }\end{array}$ & $\begin{array}{l}35163 \\
37347\end{array}$ & $\begin{array}{l}19021 \\
21640\end{array}$ & $\begin{array}{l}54 \cdot 0 \\
57 \cdot 9\end{array}$ \\
\hline \multirow{2}{*}{$\begin{array}{l}\text { 1985: } \\
\text { Jan-June } \\
\text { Guidelines introduced: } \\
\text { July-Dec }\end{array}$} & 36028 & 21296 & $59 \cdot 1$ \\
\hline & 37344 . & 18003 & $48 \cdot 2$ \\
\hline $\begin{array}{l}\text { 1986: } \\
\text { Jan-June }\end{array}$ & 36031 & 18150 & 50.3 \\
\hline
\end{tabular}

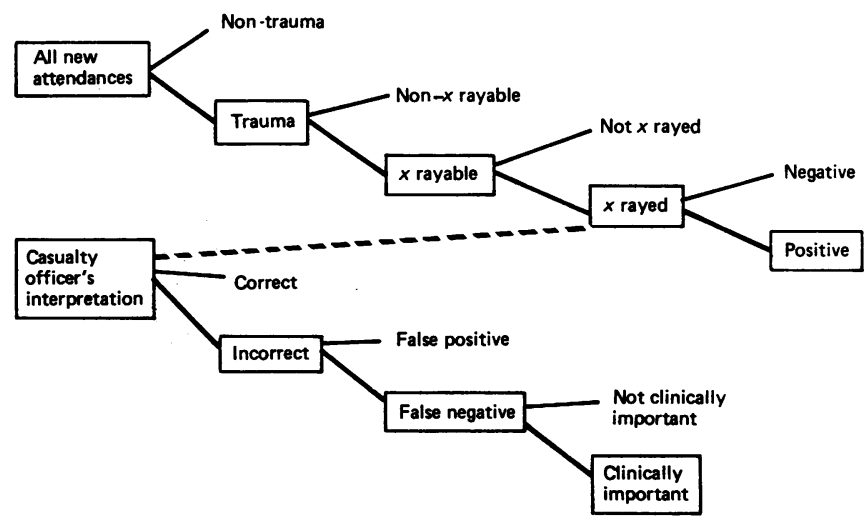

FIG 1-Algorithm applied to case analysis.

\section{REFERRAL GUIDELINES}

The upward trend in $x$ ray referral between 1982 and 1985 (table II) resulted in patients having to wait for $x$ ray examinations. In an attempt to resolve this problem we rationalised criteria for $x$ ray referral. After the study of tenured casualty officers was completed clinical guidelines were introduced to standardise the selection of patients for radiography in certain common emergencies and injuries (table III). The approval of specialists was obtained beforehand. The guidelines were overruled if a patient was referred by his or her general practitioner with a specific request for an $x$ ray examination. These patients were excluded from the study.

\section{Results}

$X$ Ray referral during tenure-During the study of tenured casualty officers $65 \%$ of new attendances were due to trauma, and $65 \%$ of these were $x$ rayed; $24 \%$ of the radiographs were "positive"-that is, showed relevant abnormality. The referral rate for the group (mean value, fig 2 ) increased significantly with experience (total $\chi^{2}=12 \cdot 77 ; 6 \mathrm{df}, \mathrm{p}=0.046 ; \chi^{2}$ for trend $=$ $5.5,1 \mathrm{df}, p=0.019$ ). The positivity (or "pick up") rate for the group did not follow a linear trend, although it dipped to its lowest value more than halfway through the study. In both referral and positivity interindividual variation was highly significant $(\mathrm{p} \ll 0.001$, two factor analysis of variance).

Interpretation of radiographs-Errors in interpretation were rare. The number of errors per doctor during each unit of experience provided figures that were too small for serial comparison. Therefore the percentage error rate for the group (erroneous interpretations as a percentage of all interpretations) was plotted against experience'(fig 3). The incidence of clinically important false negative errors was $1 \cdot 2 \%$ over the whole study, but this fell from $1.7 \%$ (13 in 751 radiographs) to $0.6 \%$ (five in 795 radiographs) during tenure. The proportion of errors (all types) decreased with experience. The reduction in the percentage of total errors, false negative errors, and clinically important false negative errors was significant $\left(\chi^{2}\right.$ for trend $=8.17$ to $14.02,1 \mathrm{df}, \mathrm{p}<0.005$ for each series). The trend in false positive errors (correctly recognising normal films) was downwards but not significant $\left(\chi^{2}\right.$ for trend $=1 \cdot 79,1 \mathrm{df}, \mathrm{p}=0 \cdot 18$ ).

Distribution of interpretation errors-The site of injury was plotted against

TABLE III-Abbreviated guidelines for $\mathrm{x}$ ray referral

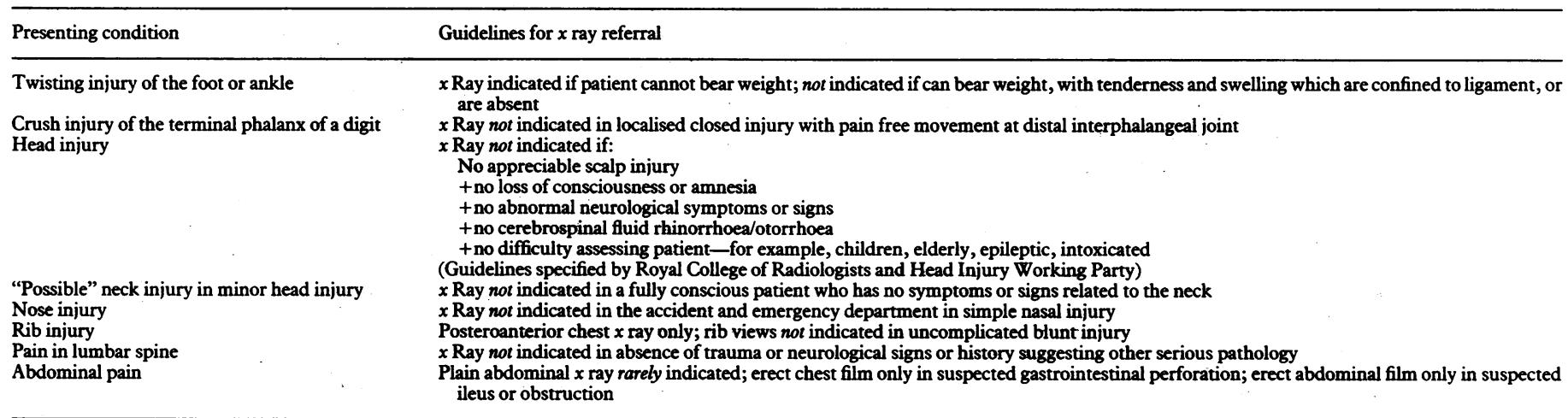




\begin{tabular}{|c|c|c|c|c|c|c|c|c|}
\hline \multirow{2}{*}{\multicolumn{3}{|c|}{ Injuries }} & \multirow{2}{*}{\multicolumn{2}{|c|}{ Positive $x$ rays }} & \multicolumn{4}{|c|}{ Errors in interpretation } \\
\hline & & & & & \multirow{2}{*}{$\begin{array}{l}\text { Clinically important } \\
\text { false negative } \\
\text { (No) }\end{array}$} & \multirow{2}{*}{$\begin{array}{c}\text { False } \\
\text { positive } \\
(\mathrm{No})\end{array}$} & \multirow{2}{*}{$\begin{array}{l}\text { Total } \\
\text { No }\end{array}$} & \multirow{2}{*}{$\begin{array}{l}\text { Total errors as \% } \\
\text { radiographs } \\
\text { of site }\end{array}$} \\
\hline Site & No & No of $x$ rays & No & $\%$ Of $x$ rays & & & & \\
\hline Skull & 696 & 384 & 7 & 2 & 0 & 2 & 2 & 0.5 \\
\hline Facial & 311 & 162 & 41 & 25 & 2 & 2 & 5 & $3 \cdot 1$ \\
\hline Nasal & 153 & 108 & 37 & 34 & 1 & 7 & 12 & $11 \cdot 1$ \\
\hline Cervical spine & 241 & 198 & 9 & 5 & 0 & 3 & 3 & 1.5 \\
\hline Shoulder & 446 & 319 & 118 & 37 & 4 & 9 & 14 & $4 \cdot 4$ \\
\hline Elbow & 286 & 224 & 55 & 25 & 10 & 12 & 25 & $11 \cdot 2$ \\
\hline Forearm & 194 & 123 & 48 & 39 & 0 & 5 & 6 & 4.9 \\
\hline Wrist & 748 & 582 & 226 & 39 & 20 & 23 & 54 & $9 \cdot 3$ \\
\hline Hand & 981 & 787 & 203 & 26 & 6 & 16 & 30 & 3.8 \\
\hline Chest & 234 & 181 & 26 & 14 & 0 & 7 & 9 & $5 \cdot 0$ \\
\hline Thoracolumbar spine & 132 & 105 & 6 & 6 & 0 & 2 & 4 & 3.8 \\
\hline Pelvis & 104 & 78 & 26 & 33 & $\mathbf{0}$ & 4 & 4 & $5 \cdot 1$ \\
\hline Knee & 416 & 289 & 34 & 12 & 1 & 8 & 9 & $3 \cdot 1$ \\
\hline Ankle & 1319 & 567 & 61 & 11 & 9 & 23 & 40 & $7 \cdot 1$ \\
\hline Foot & 1276 & 685 & 157 & 23 & 6 & 16 & 30 & $4 \cdot 4$ \\
\hline Other & 863 & 671 & 249 & 37 & 9 & 7 & 19 & $2 \cdot 8$ \\
\hline Total & 8400 & 5463 & 1303 & 24 & 68 & 146 & 266 & 4.9 \\
\hline
\end{tabular}

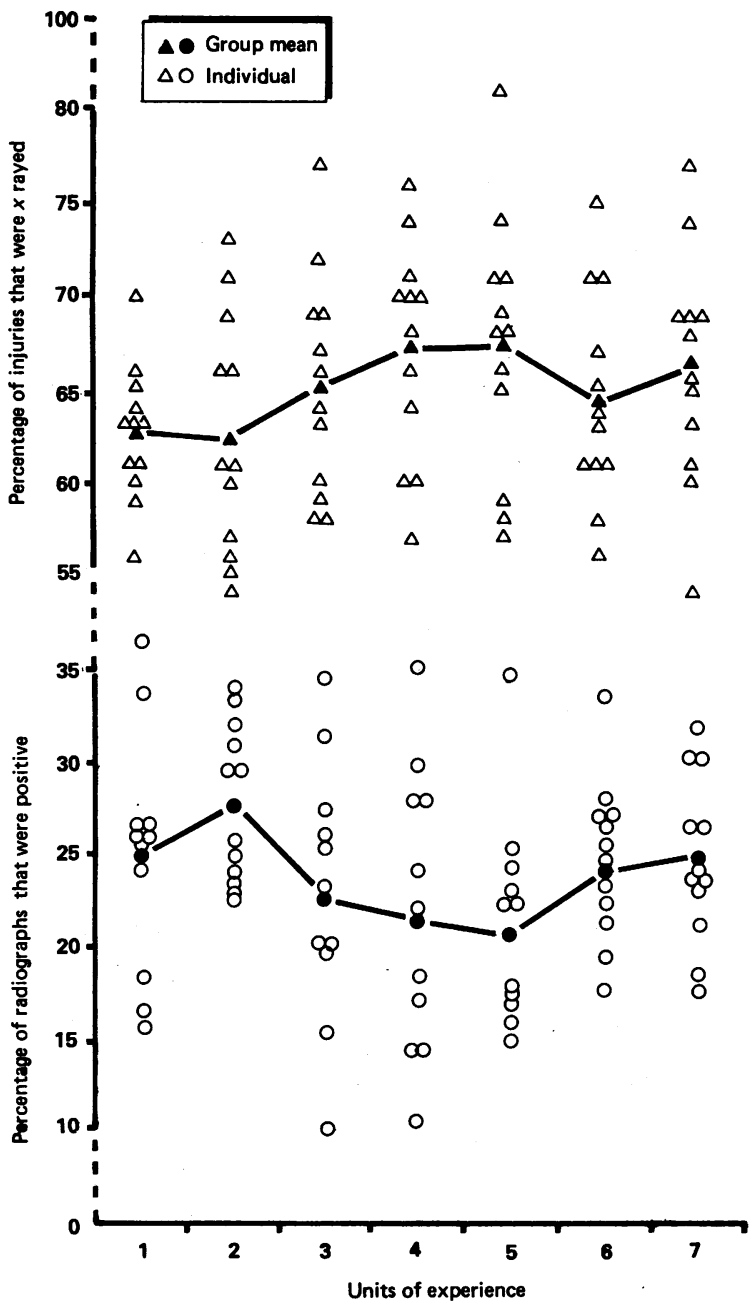

FIG 2-Referral rates and pick up (positive) rates plotted against experience of casualty officers.

the type of error (table IV). Errors were more commonly seen in common injuries. Radiographs of the wrist, ankle, hand, foot, and elbow were the most common sources of error. As a percentage of $x$ ray films taken (per site), those of the elbow, nose, wrist, and ankle had the highest error rate. The highest rates of clinically important errors were in interpretation of films of the elbow, wrist, and ankle.

Results of referral guidelines-After the guidelines were introduced the referral rate for all new attendances fell to its lowest level for three years (see table II). The reduction in the overall referral rate after the guidelines were introduced was highly significant, after adjusting for the year effect $\left(\chi^{2}=\right.$ $1262,1 \mathrm{df}, \mathrm{p} \ll 0.001)$.

One common injury was studied in an attempt to determine whether the referral guidelines had increased the incidence of missed abnormality. (The only sure way of establishing this would be to submit every patient to radiography after the casualty officer had documented his decision.)

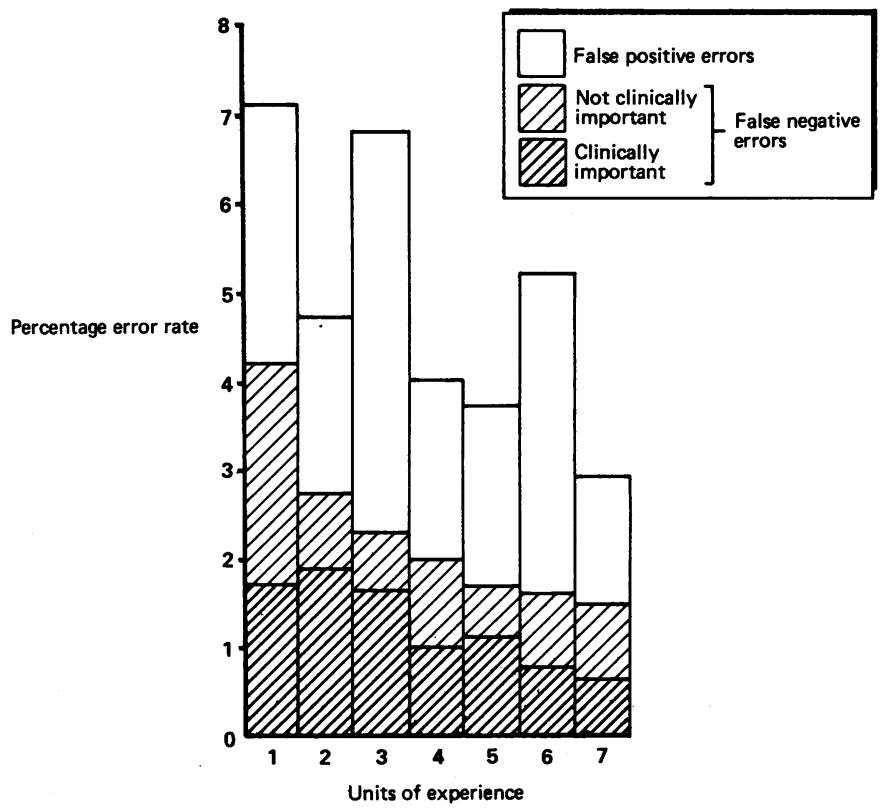

FIG 3-Errors in interpretation of radiographs plotted against experience.

Radiographs of the ankle account for up to $10 \%$ of accident and emergency $x$ ray films taken ${ }^{317}$ and $2 \%$ of those of a general hospital. ${ }^{3} \mathrm{~A}$ comparison was made of data for twisting ankle injuries in the same month of consecutive years (September 1984 and 1985, before and after the guidelines were introduced). Total number of new attendances in 1984: 6198, in 1985: 6531; twisting ankle injuries 1984: $323,1985: 436$; ankles $x$ rayed $258(80 \%$ of injuries) and $254(58 \%)$; fractures $43(17 \%$ of ankles $x$ rayed) and $58(23 \%)$; fracture incidence $13 \cdot 3 \%$ (of injuries) and $13 \cdot 3 \%$. After the referral guidelines were introduced there was a reduction in the proportion of ankles being $x$ rayed that was highly significant $\left(\chi^{2}\right.$ corrected $=385,1 \mathrm{df}, \mathrm{p}=5 \times 10^{-10}$, Yates's correction for $2 \times 2$ tables). The identical incidence of fractures, together with an unchanged rate of late error detection on patient review (clinical impression), suggest that the guidelines did not adversely affect morbidity in this injury. 


\section{Discussion}

The growing interest in the use of $x$ ray examinations by accident and emergency departments over the past 10 years ${ }^{1-17}$ has stemmed not only from the development of the specialty but also from increasing workloads in $x$ ray departments. ${ }^{18-20}$ Attempts to rationalise referral habits and to develop systems for selective yet safe $x$ ray reporting have been compounded by other factors, including the changing expectations of patients and the threat of litigation. ${ }^{218} 19$ There is no consensus of opinion at present on selecting patients for radiography or on selective reporting by radiologists.

In our department the number of new attendances increased between 1982 and 1985, but the proportion of patients being referred for $x$ ray examination increased more rapidly. This upward trend was statistically significant (total $\chi^{2}=658 \cdot 4,6 \mathrm{df} ; \chi^{2}$ for trend $=$ $548 \cdot 7,1 \mathrm{df} ; \mathrm{p} \ll 0 \cdot 001)$. During this period the number of "units per patient," a numerical representation of the type and cost of different $x$ ray examinations, based on standard Department of Health guidelines, did not alter. The number of units per patient was $12 \cdot 7$ for the whole of $1982,12.6$ for 1983 , and 12.8 for 1984 , while monthly values varied between a minimum of 11.9 and a maximum of $14 \cdot 5$. This suggests that the same types of $x$ ray examinations were being performed on more patients.

Three conclusions emerged from this study in relation to $x$ ray referral habits and the interpretation skills of casualty officers: $(a)$ Clinical experience with trauma alone did not influence positively the ability of doctors to select patients for radiography (in fact this skill deteriorated slightly). (b) Clinical experience with trauma, in addition to a teaching programme, positively influenced the ability of doctors to interpret radiographs. (c) Clinical guidelines on selecting patients for radiography for certain injuries and emergencies reduced the overall $x$ ray referral rate.

In 1980 de Lacey et al found that $7 \%$ of radiographs were incorrectly interpreted by casualty officers, ${ }^{13}$ and in 1985 Wardrope and Chennells reported $6 \cdot 2 \% .^{16}$ These studies included all new attendances in the accident department. Our error rate of $4.9 \%$ compares with Swain's of $3.9 \%$ for trauma alone. ${ }^{17}$ Clinically important errors occurred in $1.2 \%$ of interpretations in our study (Wardrope and Chennells: $1 \cdot 1 \%$ ). There was an appreciable reduction in the total number of errors, as well as in clinically important errors, during tenure of post of casualty officers in our study. The ability to identify normal radiographs improved, in accordance with another study, ${ }^{17}$ but this improvement was not significant. We strongly support earlier recommendations that all radiographs taken in the casualty department should be reviewed by an experienced radiologist. ${ }^{13-16}$

Common injuries of the extremities (elbow, wrist, hand, ankle, and foot) provided most of the radiological errors in this study. Radiographs of the elbow, wrist, and ankle most often produced errors of clinical importance, in agreement with earlier studies. ${ }^{10} 13.15$ They and $x$ ray films of the nasal bone were also the most frequent sources of false positive errors (interpreting a normal film as abnormal). Although false positive errors are rarely clinically serious, they waste resources, may cause distress to patients and relatives, and may even provoke litigation. Furthermore, in certain injuries and emergencies radiography is now widely considered unnecessary, usually because treatment is not affected by the findings. This is so for nasal injuries, ${ }^{21}$ soft tissue ankle injuries, ${ }^{35-711}$ certain head injuries, ${ }^{922-24}$ erect films in most acute abdomens, ${ }^{425}$ and rib views in blunt chest trauma. ${ }^{26}$ These factors gave further stimulus to the planning of guidelines for referral.

During casualty officers' tenure of post there was an initial rise in referral rate. Although they received teaching on the interpretation of radiographs and on the management of injuries, there was none specifically on selecting patients for radiography. The initial rise in referral rate may have been due to several factors. At the start of tenure an error of interpretation might lead a casualty officer to "widen the net" and refer more patients for radiography. A similar response might follow direct or indirect concern in a patient's complaint or litigation. This would have no effect on occasional, but almost inevitable, errors of interpretation, but would of course increase the workload of the $x$ ray department. It might be argued that heightened awareness of errors and their consequences would make doctors less selective in the early part of their tenure, and a regular $x$ ray audit might exacerbate this tendency.

Interpretation skills were good and compared closely with earlier reports. ${ }^{131617}$ The way to minimise errors is not to request more $x$ rays but to pay greater attention to detail in both clinical assessment and in interpretation of radiographs. ${ }^{15}$ The distinction between patient selection for radiography, based on clinical findings, and radiological interpretation should receive greater emphasis in the training of casualty officers. Applying specific and standardised criteria for $x$ ray referral may go some way towards clarifying this distinction. The substantial fall in overall referral rate in this department after the implementation of such guidelines was not accompanied by a rise in morbidity.

In a recent study the Royal College of Radiologists found no evidence of the overuse of radiography of extremities in eight accident and emergency units despite "marked differences in clinical practice between centres." 10 Although "clinical examination was found to be not entirely reliable at identifying extremity fractures," the authors were in favour of guidelines for radiography of arms and legs along the lines now widely applied to preoperative chest radiography and skull radiography in head injury. ${ }^{9223}$ Reports, however, on selection criteria and their value in ankle injuries, for example, are at variance. ${ }^{35-811}$ Clinical examination was considered sufficiently reliable at distinguishing bony from nonbony injury by some ${ }^{5811}$ but not by others. ${ }^{7}$ Absence of swelling over the lateral malleolus was considered by some ${ }^{311}$ but not by others ${ }^{8}$ to be a reliable means of excluding fracture. The value of point tenderness is also contentious. Some have found it useful as a positive finding when confined to the lateral malleolus, ${ }^{38}{ }^{11}$ whereas others have found it useful as a negative finding when confined to the lateral collateral ligament. ${ }^{5.711}$ The only clinical criterion about which there is consensus is the ability to bear weight. ${ }^{35.811}$ This illustrates the difficulties in devising clinical guidelines for $x$ ray referral in trauma - even in this common injury of a weight bearing joint. The Royal College of Radiologists reported that it costs on average $£ 40$ to detect an extremity fracture, ${ }^{10}$ whereas it cost $£ 900$ to $£ 1100$ to detect a skull fracture before the introduction of guidelines for skull radiography. ${ }^{23} 2427$ Extremities, however, are $x$ rayed more often than skulls. The introduction of clinical guidelines for radiography not confined to extremity trauma has appreciably reduced the workload in this $x$ ray department and is producing estimated savings of $£ 18000$ a year.

The results of this study indicate that it is possible to influence positively not only the interpretation skills but also the referral habits of doctors in relation to $x$ ray examinations in accident and emergency departments. The distinction between these two facets of radiodiagnosis must be clearly emphasised. Guidelines for $x$ ray referral may help to clarify and maintain this distinction, and implementing guidelines in this department has increased both the quality and efficiency of service.

We thank Dr Jane L Sutton and MrCR West, departments of community health and statistical and computation mathematics, University of Liverpool; Mr David Cope, superintendent radiographer, Walton Hospital; and Mrs Pat Broadhead and Miss Julie Dillon, medical secretaries, Walton Hospital, for their help.

\section{References}

1 de Lacey GJ. Clinical and economic aspects of the use of $x$-rays in the accident and emergency department. Proceedings of the Royal Society of Medicine 1976;69:755.

2 de Lacey GJ, Barker A, Wignall BK, Reidy JR, Harper J. Reasons for requesting radiographs in an accident department. BrMed f 1979; i:1595-7.

3 de Lacey GJ, Bradbrooke $S$. Rationalising requests for $x$-ray examination of acute ankle injuries. BrMed f 1979;i:1597-8.

4 de Lacey GJ, Wignall BK, Bradbrooke S, Reidy JR, Hussain S, Cramer B. Rationalising abdominal radiography in the accident and emergency department. Clin Radiol 1980:31:453-5.

Brand DA, Frazier WH, Kohlhepp WC at A protocol for selecting patients with iniured extremities who need $\mathrm{x}$-rays. $N$ Engl $\mathcal{F}$ Med 1982;306:333-9.

6 Brooks SC, Potrer BT, Rainey JB. Inversion iniuries of the ankle: clinical assessment and radiographic review. Br Med f 1981;282:607-8.

Stother I. Incidence of minor fractures in twisting injuries of the ankle. Injury 1974;5:213-4.

8 Vargish T, Clarke WR, Young RA, Jensen A. The ankle injury-indications for the selective use of $\mathrm{x}$-rays. Injury 1983;14:507-12. 
9 Royal College of Radiologists. Patient selection for skull radiography in uncomplicated head injury. Lancet 1983;i:115-8.

10 Royal College of Radiologists. Radiography of injured arms and legs in eight accident and emergency units in England and Wales. Br Med f 1985;291:1325-8.

11 Dunlop MG, Beattie TF, White GK, Raab GM, Doull RI. Guidelines for selective radiological assessment of inversion ankle injuries. $\mathrm{Br} M e d \mathcal{F}$ 1986;293:603-5.

12 Anonymous. Must radiologists do all the reporting [Editorial]? Br $\mathcal{F}$ Radiol 1975;48:517.

13 de Lacey GJ, Barker A, Harper J, Wignall BK. An assessment of the clinical effects of reporting accident and emergency radiographs. Br $\mathcal{F}$ Radiol 1980;53:304-9.

14 Mucci $B$. The selective reporting of $x$-ray films from the accident and emergency department. Injury 1983;14:343-4.

15 Guly HR. Missed diagnosis in an accident and emergency department. Injury 1984;15:403-6.

16 Wardrope J, Chennells PM. Should all casualty radiographs be reviewed? $\mathrm{Br}$ Med $\mathcal{J}$ 1985;290:1638-40.

17 Swain AH. Radiological audit-changes in casualty officer performance during tenure of post. British foumal of Accident and Emergency Medicine 1986;1 (2):5-9.

18 Raison JCA. Medical and legal aspects of the increasing demand for diagnostic radiology. Proceedings of the Royal Society of Medicine 1976;69:755-6.
19 Evans KT. The radiologist's dilemma. Br $\mathcal{F}$ Radiol 1977;50:299-301

20 Golberg B. Department of inappropriate investigations. Br Med f 1977;ii:1274-5.

21 de Lacey GJ, Wignall BK, Hussain S, Reidy JR. The radiology of nasal injuries: problems of interpretation and clinical relevance. Brf Radiol 1977;50:412-4.

22 Royal College of Radiologists. A study of the utilisation of skull radiography in nine accident and emergency units in the UK. Lancet 1980;ii:1234-6.

23 Royal College of Radiologists. Costs and benefits of skull radiography for head injury. Lancet 1981;ii:791-5.

24 Royal College of Radiologists. Patient selection for skull radiography in uncomplicated head injury. A national study. Lancet $1983 ;$; $115-8$.

25 Hayward MWJ, Hayward C, Ennis WP, Roberts CJ. A pilot evaluation of radiography of the acute abdomen. Clin Radiol 1984;35:289-91.

26 Danher J, Eyes BE, Kumar K. Oblique rib views after blunt chest trauma: an unnecessary routine? BrMed f 1984;289:1271.

27 Roberts CJ. Medical care as a risk avoidance procedure: underwriting the cost of care in the UK. BrMed F 1982;285:751-5.

(Accepted 19 January 1987)

\title{
Clinical Algorithms
}

\section{Irregular vaginal bleeding}

\author{
GEOFFREY CHAMBERLAIN
}

Abnormal bleeding from the vagina is generally classified as regular or irregular. Regular bleeding occurs in the same rhythmical pattern as menstrual bleeding, but the loss is prolonged or heavier; irregular bleeding comes at any time and bears no relation to the usual pattern. Regular vaginal bleeding is usually related to functional hormonal changes, whereas irregular vaginal bleeding is often associated with surface lesions of the genital tract. Bleeding from the lower genital tract (below and including the external cervical os) is often the result of mild contact at vaginal examination or intercourse. Treatment depends on correct diagnosis, which in turn is based on the classic approach of history, appropriate examination, and investigations.

\section{History}

The pattern of blood loss should be established. The volume of blood may vary from a thin smear to a quite heavy loss of up to 200 $\mathrm{ml}$. An irregular brown discharge represents old blood which has had time to collect in the genital tract after it has left the capillary circulation so that the haemoglobin is denatured.

\section{CONTRACEPTION}

Methods of contraception should be noted. Progesterone only pills, low dose combination oral contraceptives, intrauterine contraceptive devices, and depot progestogens may all cause small irregular withdrawal bleeds. Management of these patients

St George's Hospital Medical School, London SW17 ORE

GEOFFREY CHAMBERLAIN, FRCS, FRCOG, professor of obstetrics and gynaecology is covered in the algorithm on contraception by Kubba and Guillebaud.'

\section{Examination}

All women should have a general examination including a pelvic examination. This allows bimanual assessment of the uterus, adnexae, and the posterior part of the pelvis. A visual inspection of the cervix, the fornices, the vagina, and the vulva must also be made with a speculum, and a cervical smear should be obtained. Management of patients with abnormal smears is discussed in the algorithm on the abnormal smear by Singer. ${ }^{2}$

\section{LESIONS OF THE VULVA AND VAGINA}

A surface lesion on the vulva or vagina may be caused by an infection. Monilial infection can result in raw areas of the lower genital tract to which matted webs of fungus stick. When these are separated irregular bleeding may follow. The diagnosis can often be made with the naked eye but should be confirmed by microscopical examination. The patient should be treated with appropriate antifungal agents. Rawness of the vulva or vagina may be the result of a trichomonal infection or from scratching the associated itch. This again may be suspected clinically from the appearance of the greenish, frothy discharge or the pungent smell. The diagnosis should be confirmed by microscopical examination and the patient and her partner treated with appropriate antitrichomonal agents.

Varicose veins may be seen on the vulva or, less commonly, on the lower part of the vagina. They are obvious and bleeding may occasionally occur. Blood loss may be extensive but is more often slight and occurs after intercourse, especially during pregnancy. If the veins are accessible compression can be obtained using two external tampons held firmly in place on the vulva by a strap of elastic $2.5 \mathrm{~cm}$ wide along the front of the body, over the shoulder, and down the back. This is really first aid treatment, however, and injection of a sclerosing agent may be required. Occasionally, 